\title{
Effect of processing parameters on the formability of recycle friendly AA5754 alloy
}

\author{
Sazol Das ${ }^{1 *}$, Matthew Heyen ${ }^{1}$, John $\mathrm{Ho}^{1}$, and ChangOok Son ${ }^{1}$ \\ ${ }^{1}$ Novelis Global Research and Technology Center, Kennesaw, GA 30144, USA
}

\begin{abstract}
AA5xxx series Al-Mg alloys possess good combination of high specific strength-to-weight ratio, formability and corrosion resistance, which makes them attractive to the automakers for their light weighting needs. Increasingly the automakers are demanding sustainable materials. Developing aluminum alloys with increased recycled content is becoming imperative. However, increasing the recycled content can negatively impact the overall formability and joinability of the alloy. Formability is important in the shaping of complex parts and it is a key requirement in automotive manufacturing. Similarly, the other key requirement for automotive sheet is joinability. Self-piercing riveting (SPR) technology is increasingly being used for joining. In this study, the process optimization of high recycle content AA5754 alloy's for formability and rivetability will be discussed. Controlling the annealing heat treatment to produce optimum combination of grain size along with balanced recrystallized and rolling texture to improve the SPR joint configuration will be presented.
\end{abstract}

\section{Introduction}

Aluminum alloys have attracted considerable interest from the automotive industry in the last two decades as manufacturers seek to design lightweight vehicles with improved fuel efficiency and reduced vehicle emissions [1]. Materials for lightweight construction in automotive manufacturing must meet complex requirements. However, it is essential to combine good formability with in-service strength, excellent corrosion resistance, joinability, and crash worthiness [2]. The automotive structural inners and outers can be a sustainable material of choice due to its high value scrap from stamping trimmings as well as end-of-life vehicle scrap. However, a high level of $\mathrm{Fe}, \mathrm{Mn}, \mathrm{Si}$ and other minor alloying elements resulting from from scrap mixing can decrease the overall formability of the alloy. For example, Fe has a very limited solubility $(0.052 \mathrm{wt} . \%)$ at the eutectic temperature, which leads to excess $\mathrm{Fe}$ to form constituent particles with $\mathrm{Mn}$ and Si that deteriorates the mechanical and fracture behavior of the alloys during forming [3 - 4]. Thus, the success of using aluminum as weight saving material depends on developing a very clear understanding of physical metallurgy behind it.

Automakers prefer AA5754 aluminum alloy for inner and structural applications in vehicles due to its good combination of moderate strength and formability. AA5754 aluminum alloy's strengthen form solid solution strengthening and can be easily formed in fully annealed condition (O Temper). However, the formability can be negatively affected by the increased scrap usage in the remelting process. A scrap metal containing high $\mathrm{Fe}, \mathrm{Mn}$ and $\mathrm{Si}$, can lead to poor forming performance [3]. To explore the full potential of recycled content (Fe, Mn and $\mathrm{Si}$ ) on the formability, AA5754 alloy was designed and processed with two different levels of $\mathrm{Fe}, \mathrm{Mn}, \mathrm{Si}$ and other minor alloying element.

\section{Procedures and experiments}

Industrial scale full size direct chill (DC) ingots of AA5754 were cast with two different levels of minor alloying additions. The chemical compositions of these ingots were determined by inductively coupled plasma analysis (ICP) and the ranges are reported in Table 1 . Variant B (A with increased Fe, Mn, Si etc.) contained more minor alloying elements compared to variant $\mathrm{A}$.

Table 1. Chemical compositions of the ingots for both alloys.

\begin{tabular}{|c|c|c|c|c|c|c|}
\hline & Si & Fe & Cu & Mn & Mg & Cr \\
\hline \multirow{3}{*}{ Alloy A } & 0.05 & 0.05 & 0.01 & 0.20 & 3.10 & 0.01 \\
& - & - & - & - & - & - \\
\hline \multirow{3}{*}{ Alloy B } & 0.10 & 0.10 & 0.05 & 0.30 & 3.20 & 0.03 \\
& - & 0.08 & 0.06 & 0.25 & 3.15 & 0.04 \\
& 0.18 & 0.18 & - & - & - & - \\
\hline
\end{tabular}

Ingots were scalped, homogenized, hot rolled (HR) and cold rolled (CR) using standard practice. The cold rolled samples were then continuously annealed using standard peak metal temperature (PMT) as well as 20, 40, 50 $80^{\circ} \mathrm{C}$ higher PMT over the standard practice to obtain $\mathrm{O}$ temper. Standard (ASTM B557 2" GL) tensile tests were

Corresponding author: sazol.das@novelis.adityabirla.com 
performed for both variants in the longitudinal (L), transverse (T) and diagonal (D) orientations. Selfpiercing riveting (SPR) for both alloys was performed using Henrob rivet gun to evaluate SPR performance and the impact of recycled content on formability.

Optical microscopy (OM) was used to conduct a detailed microstructural study of the size and distribution of constituent particles in the final gauge samples. To observe the grain structure under $\mathrm{OM}$ samples were electrolytically etched using Barker's reagent. Grain sizes were measured using ASTM standard for all conditions. Various microstructural features, including the different types and spatial distributions of constituent phases, and their relative sizes and area fractions, were characterized in the $\mathrm{O}$ - temper samples using a Philips XL-40 field emission gun scanning electron microscope (FEG-SEM) in back-scattered electron (BE) imaging mode together with an Oxford Instruments energy dispersive X-ray spectroscopy (EDXS) system. Texture component of these $\mathrm{O}$ temper samples were analyzed to determine ratio between recrystallization ( $\alpha$ - fiber) and deformation texture ( $\beta$ - fiber) using Panalitycal texture goniometer.

\section{Results and discussions}

Detailed mechanical property, riveting, microstructural features and texture component data obtained from the study are summarized below with critical observations.

\subsection{Mechanical properties}

Tensile properties in O temper after standard annealing practice shows some noticeable difference in strength and elongation for addition of recycled content in Alloy B. Alloy B measured $10-15 \mathrm{MPa}$ higher strength and 1 $-2 \%$ lower elongation compared to alloy A (Fig. 1).

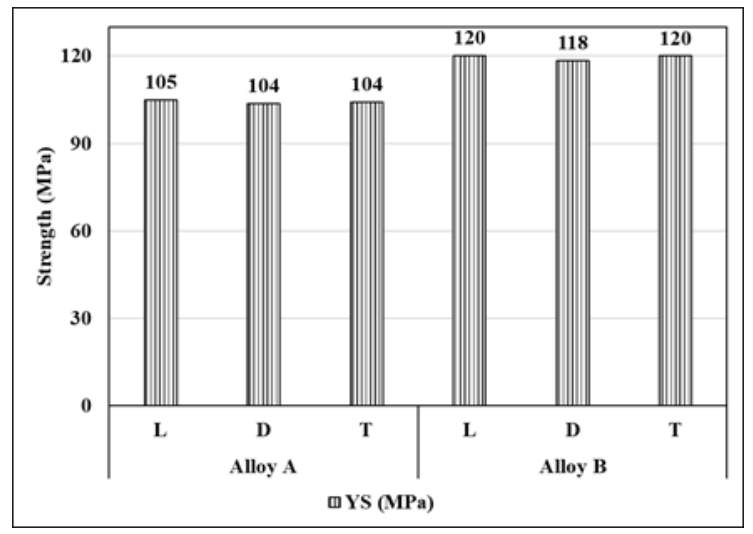

a)

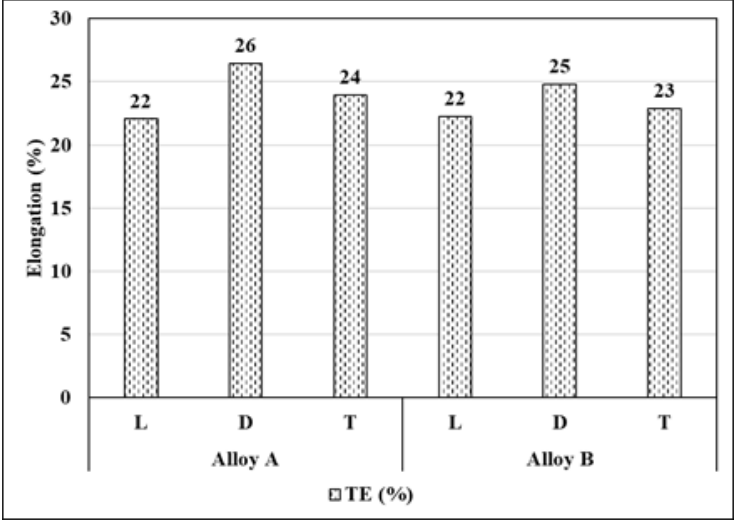

b)

Fig. 1. Tensile properties of both alloys after standard annealing practice in $\mathrm{L}, \mathrm{T}$ and $\mathrm{D}$ orientation: a) yield strength and b) elongation.

The increase in strength with lower elongation is caused by the change in recrystallization behavior due to addition of minor alloying additions ( $\mathrm{Mn}$ and $\mathrm{Cr}$ ). $\mathrm{Mn}$ and $\mathrm{Cr}$ are both known to form dispersoids during homogenization and the dispersoids inhibit recrystallization by pinning the grain boundaries [5]. Strength and elongation of alloy B after various PMT annealing are shown for L orientation in Fig. 2.

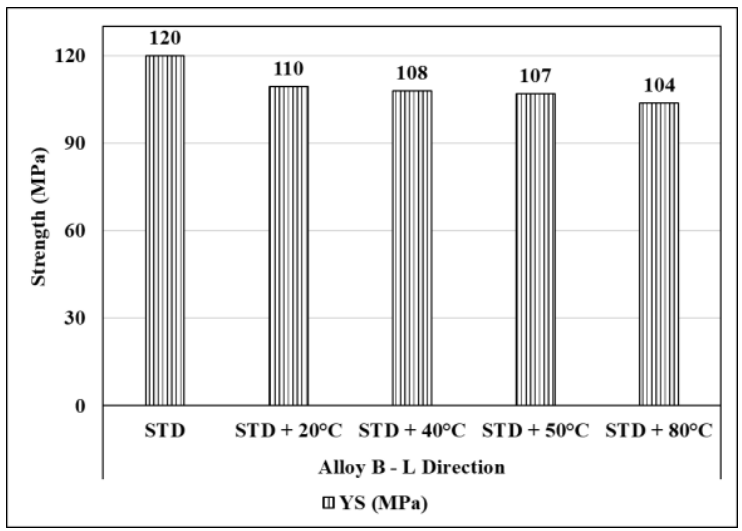

a)

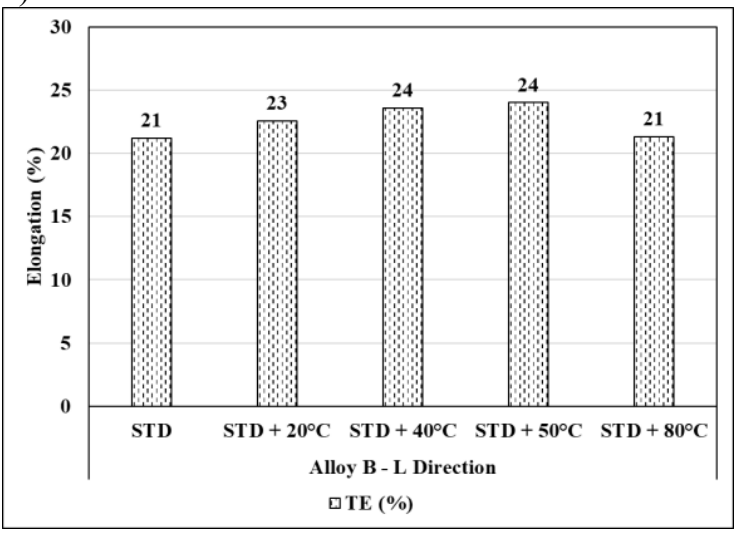

b)

Fig. 2. Tensile properties of alloy B after various PMT annealing in L orientation: a) yield strength and b) elongation.

High temperature annealing appears to lower the strength gradually. This might be due to the change in 
recrystallization and grain coarsening. However, elongation changes with increasing annealing PMT was not consistent. Drop in the elongation was observed after highest annealing PMT. This change in elongation is the resultant effect of fast heating rate, which might alter the grain size or texture within the bulk material.

\subsection{Joining assessment}

Figure 3 shows cross-sections of both alloys after SPR assembly in 3 -stack configuration where AA6451 occupies top two layers and AA5754 sits at the bottom to reflect structural joints in a vehicle. Standard annealing practice shows alloy B suffers from bottom thinning whereas alloy A retains more than 100 um bottom layer thickness after riveting (Fig. 3a and 3b). SPR for alloy B was performed with high annealing PMT's and their cross-sections showed better material retention at the bottom layer compared to standard annealing for $40^{\circ} \mathrm{C}$ higher PMT (Fig. 3c). However, the bottom thinning get more severe for $80^{\circ} \mathrm{C}$ higher PMT (Fig. 3d).
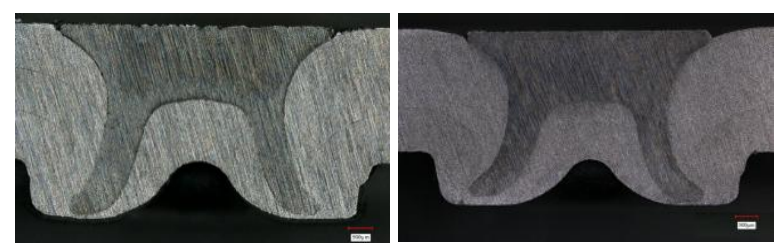

a)

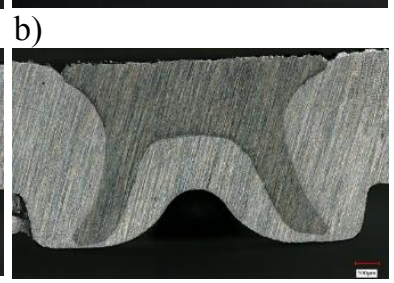

c)

d)

Fig. 3. SPR cross-section after various PMT annealing: a) alloy A - standard, b) alloy $-\mathrm{B}$ standard, c) alloy B - standard + $40^{\circ} \mathrm{C}$ and d) alloy $\mathrm{B}-$ standard $+80^{\circ} \mathrm{C}$.

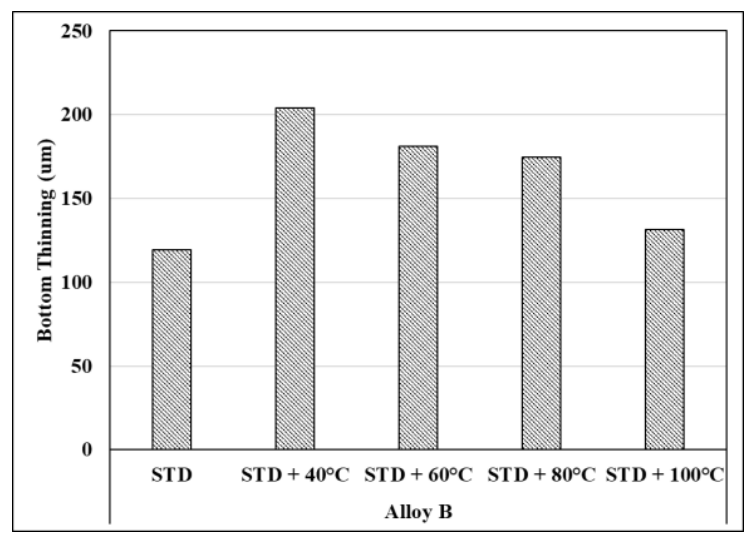

Fig. 4. Bottom thinning measurements of alloy B after various PMT annealing.

Fig. 4 is showing bottom thinning measurement for alloy $\mathrm{B}$ with various annealing temperatures. Bottom thinning gets better with increased annealing PMT over the standard practice. However, drop in thinning observed with highest annealing $\mathrm{PMT}\left(100^{\circ} \mathrm{C}\right.$ higher than standard). Similar observations were made for elongation for alloy $\mathrm{B}$ with various annealing temperatures. Detailed microstructural evaluation including grain size and texture analyses were done to understand the mechanism for this thinning behaviour.

\subsection{Microstructural observations}

Particle distributions and grain structures from OM observation are shown for both alloys in Fig. 5 with standard annealing practice.

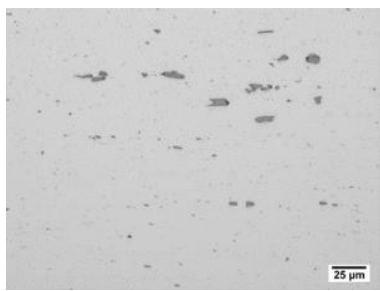

a)

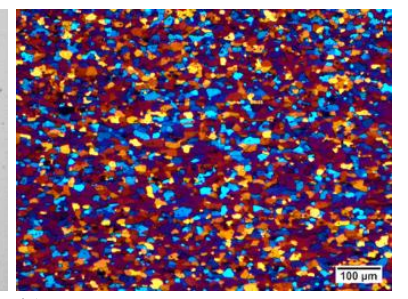

b)

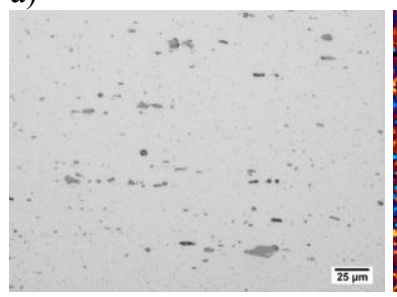

c)

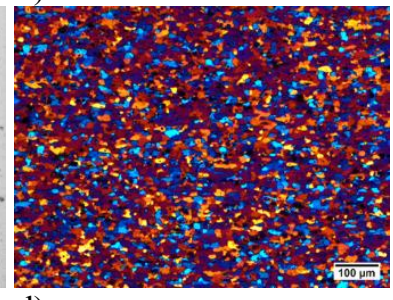

d)

Fig. 5. Microstructure in longitudinal cross-section after standard annealing practice for alloy A: a) particle distribution, b) grain structure and alloy B: c) particle distribution, d) grain structure

Alloy B shows coarse Fe constituent features compared with alloy $\mathrm{A}$. The increase in $\mathrm{Fe}$ - constituents are due to high recycled content ( $\mathrm{Fe}, \mathrm{Mn}, \mathrm{Si}$ etc.) in alloy $\mathrm{B}$ compared with alloy A. Grain sizes of alloy B were about $2-3 \mu \mathrm{m}$ smaller compared to alloy $\mathrm{A}$ for the same reason. More Fe and $\mathrm{Mn}$ results in the formation of more constituent particles, which in turn provides heterogeneous nucleation sites for particle-stimulated nucleation $(P S N)$ of recrystallized grains during annealing. This results in an overall finer grain size distribution in alloy B. Particles and grain structure of alloy B were analyzed after high temperature annealing (Fig. 6).

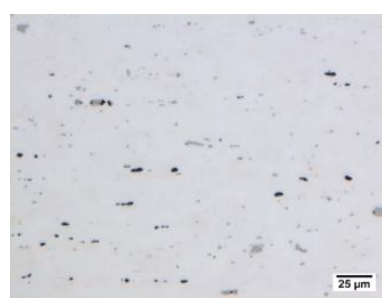

a)

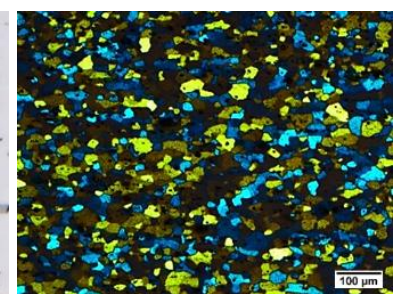

b) 


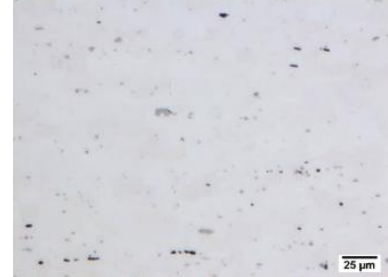

c)

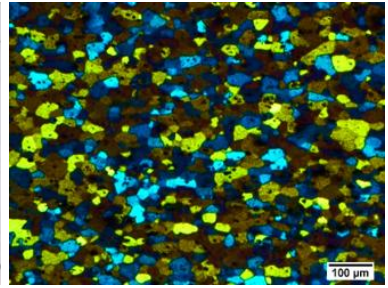

d)

Fig. 6. Microstructure in longitudinal cross-section after various PMT annealing of alloy $\mathrm{B}$ for std $+40^{\circ} \mathrm{C}$ : a) particle distribution b) grain structure and for std $+80^{\circ} \mathrm{C} \mathrm{B}$ : c) particle distribution, d) grain structure.

There was negligible effect of high annealing temperature on particle distribution, which was expected. However, grain coarsening (around $14 \mu \mathrm{m}$ compared to $10 \mu \mathrm{m}$ for standard practice) observed for very high temperature annealing.

High-resolution SEM images in back-scattered electron (BE) contrast were taken to observe the morphology of Fe constituents between alloy A and B. Higher Fe and $\mathrm{Mn}$ results in the formation of coarse constituents (grey contrast) in alloy $\mathrm{B}$ with some $\mathrm{Mg}_{2} \mathrm{Si}$ (dark contrast) particles due higher Si content (Fig. 7).

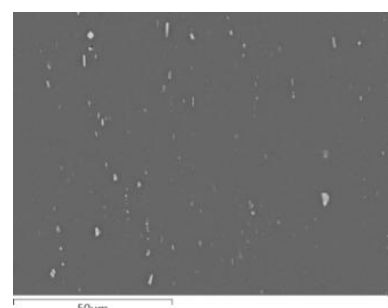

a)

Fig. 7. SEM BE images in longitudinal cross-section after standard annealing for both alloys: a) alloy A and b) alloy B

The constituent phases in alloys A and B were quantified using Feature Detection and Characterization (FDC) analysis from 50 random fields for each sample and processed to obtain size and number distribution. Fig. 8 shows constituents phase area fraction and number density and size distribution against equivalent circular diameter (ECD) for both alloys in final gauge after standard annealing practice. Alloy $\mathrm{B}$ shows large numbers of coarse constituent particles compared to alloy A as seen in micrographs (Fig. 5, 7).

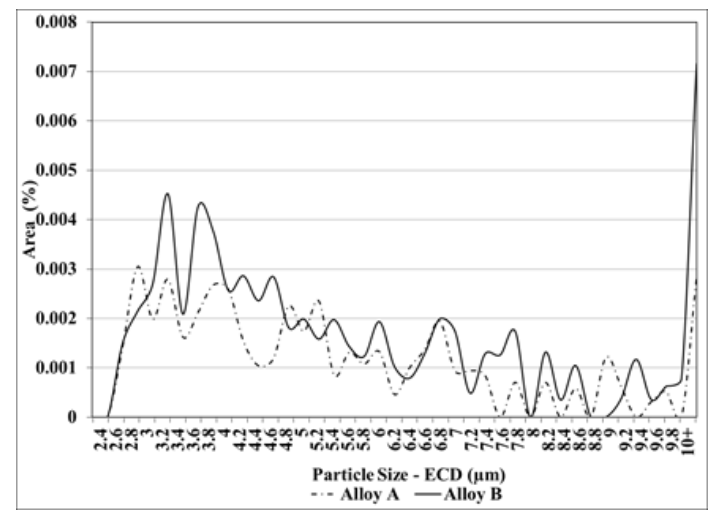

a)

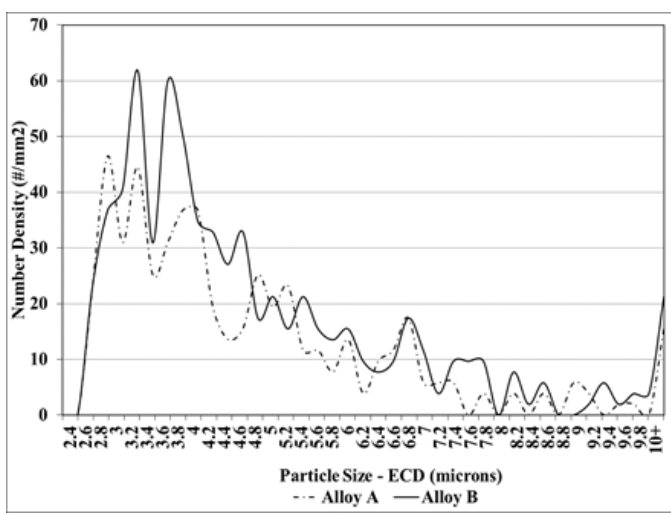

b)

Fig. 8. Constituent particle distribution after standard annealing practice for both alloys: a) area fraction and b) number density.

Recrystallization, $\alpha$ - fiber (cube and goss) and deformation, $\beta$ - fiber (brass, copper, S) texture component for bulk microstructure were measured for alloy B after different annealing temperature. Fig. 9 shows that recrystallization texture drops after high temperature annealing compared to standard annealing practice.

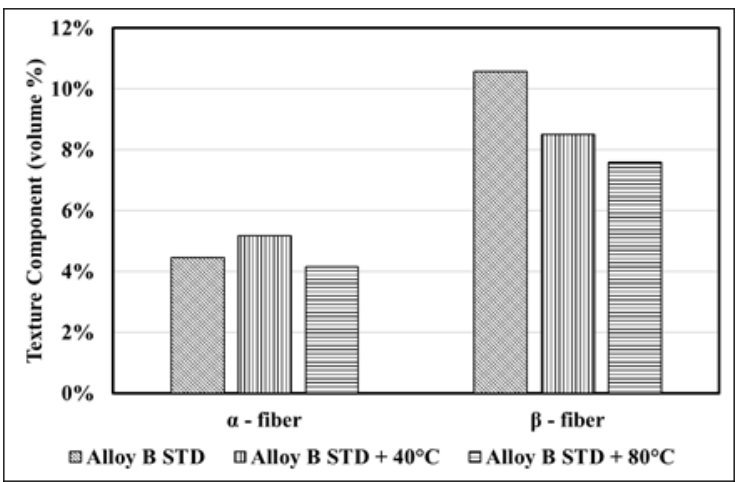

Fig. 9. Crystallographic texture for alloy $B$ after various PMT annealing.

However, deformation texture continue to drop at high annealing temperatures. A good balance of recrystallization and deformation texture is necessary for better formability, which explains why elongation and bottom thinning get worse after high annealing temperature.

\section{Conclusion}

Increase in recycled content can lead to formation of coarse Fe constituent particles along with finer grains due to PSN and grain boundary pinning by dispersoids formed during homogenization. These dispersoids can also inhibit recrystallization, which results in high strength and low elongation. Forming and joinability of recycled materials are compromised if processed through standard processing routes. Raising annealing temperature can help to produce a balanced recrystallization and deformation texture, which results in better SPR performance. Too high annealing temperature on the contrary will lead to grain growth and 
an imbalance in the bulk texture resulting in lower formability.

The authors would like to acknowledge the expert support from staff in the metallography, electron optics, application technology, mechanical testing laboratories at the Novelis Global Research and Technology Center (NGRTC) and the support of operations personnel at the Novelis Oswego works.

\section{References}

1. L. Mattei et al., Mater. Sci. Eng. A 559, 812 (2013)

2. L. E. Elend et al., Automotive Circle International, Bad Nauheim, Germany, May (2011)

3. J. Sarkar et al., Mater. Sci. Eng., A 316, 52 (2001)

4. W. B. Lievers et al., Mater. Sci. Eng. A 361, 312 (2003)

5. G. W. Zhang et al., Mater. Sci. For. 877, 172 (2016) 